Published in final edited form as:

Health Place. 2011 January ; 17(1): . doi:10.1016/j.healthplace.2010.11.006.

\title{
Neighborhood ethnic density and preterm birth across seven ethnic groups in New York City
}

\author{
Susan M. Mason a,b, ${ }^{\star}$, Jay S. Kaufmann ${ }^{a, b, c}$, Julie L. Daniels ${ }^{a}$, Michael E. Emch ${ }^{b, d}$, Vijaya K. \\ Hogan $^{\mathrm{e}}$, and David A. Savitz \\ Susan M. Mason: smason4@bics.bwh.harvard.edu; Jay S. Kaufman: jay.kaufman@mcgill.ca; Julie L. Daniels: \\ julie_daniels@unc.edu; Michael E. Emch: emch@email.unc.edu; Vijaya K. Hogan: vhogan@email.unc.edu; David A. \\ Savitz: david.savitz@mssm.edu \\ aDepartment of Epidemiology, University of North Carolina at Chapel Hill CB 7435, 2101 \\ McGavran-Greenberg Hall, Chapel Hill, NC 27599-7435, USA \\ ${ }^{b}$ Carolina Population Center, University of North Carolina at Chapel Hill CB 8120, 123 West \\ Franklin Street, Chapel Hill, NC 27516-2524, USA \\ 'Department of Epidemiology, Biostatistics, and Occupational Health, McGill University, 1020 \\ Pine Ave West, Montreal, Quebec H3A 1 A2 Canada \\ dDepartment of Geography, University of North Carolina at Chapel Hill CB3220, Saunders Hall, \\ Chapel Hill, NC 27599-3220, USA \\ eDepartment of Maternal and Child Health, University of North Carolina at Chapel Hill CB 7445, \\ 401 Rosenau Hall, Chapel Hill, NC 27599-7445, USA \\ fDisease Prevention and Public Health Institute, Mount Sinai School of Medicine, One Gustave L \\ Levy Place Box 1057, New York, NY 10029-6574, USA
}

\section{Abstract}

Residential segregation limits non-white ethnic groups' access to white neighborhood resources, but may also reduce their exposure to discrimination and facilitate social support. We computed adjusted preterm birth risk differences (RDs) for seven ethnic groups comparing $>25 \%$ to $\leq 25 \%$ ethnic density neighborhoods using 1995-2003 New York City birth records and a spatial ethnic density measure. RDs ranged from -15.0 per 1000 (95\% CI: -18.5, -11.4) for whites to 6.4 per 1000 (95\% CI: 2.8, 9.9) for blacks, with Hispanic and Asian estimates falling in between but tending to be protective. Results suggest that ethnic density is uniquely harmful for non-Hispanic blacks.

\section{Keywords}

Race; Ethnicity; Ethnic density; Residential segregation; Preterm birth; Birth outcomes

\section{(C) 2010 Elsevier Ltd. All rights reserved.}

*Corresponding author. Present address: Connor's Center for Women's Health and Gender Biology, Brigham \& Women's Hospital/ Harvard Medical School, 1620 Tremont St 3rd Floor, Boston, MA 02120, USA. Tel.: +1 617525 9684; fax: +1 6175257746.

Appendix A. Supplementary material: Supplementary data associated with this article can be found in the online version at doi: 10.1016/j.healthplace.2010.11.006. 


\section{Background}

Racial and ethnic residential segregation is deeply entrenched and widespread in the social geography of the United States (Massey and Denton, 1987; Fong and Shibuya, 2005; Massey and Denton, 1989), with some areas so segregated that they have been compared to apartheid-era South Africa (Massey, 1990). Social and health science research in the US has documented links between segregation and a variety of social and physical ills in the black population (Cutler and Glaeser, 1997; Grady, 2006; Morenoff, 2003; Ellen, 2000; Baker and Hellerstedt, 2006; Polednak, 1991; Laveist, 1989; Polednak, 1996; Guest et al., 1998; Collins and Williams, 1999; Cooper et al., 2001; Hart et al., 1998; Jackson et al., 2000; Huie et al., 2002; LeClere et al., 1997; Polednak, 1993; McCord and Freeman, 1990; White and Borrell, 2006; Subramanian et al., 2005; Morello-Frosch and Jesdale, 2006; AcevedoGarcia, 2001; Chang, 2006; Peterson and Krivo, 1999; Mason et al., 2009). From a perspective that privileges material resources as the means to health (Lynch, 2000), the observed harms of segregation are unsurprising, given the historical discrimination of blacks in employment and education that segregation has facilitated. From a psychosocial standpoint (Pickett and Wilkinson, 2008), however, black neighborhoods might benefit their residents by limiting stigmatizing inter-racial interactions, facilitating social networks, or providing a context for political organizing (Sampson and Groves, 1989; Hutchinson et al., 1996; Putnam, 2007; Bledsoe et al., 1995). Indeed, a handful of epidemiologic studies have documented better black birth outcomes (Bell et al., 2006; Roberts, 1997) and lower black mortality (Fang et al., 1998; Inagami et al., 2006) in majority-black compared to more heterogeneous neighborhoods.

Among less-studied groups such as Hispanic and Asian immigrants, for whom segregation may arise more from patterns of chain migration than from historical oppression, ethnic density may be less detrimental than it is among black Americans (Morenoff, 2003; Jenny et al., 2001; Gorman, 1999; Osypuk et al., 2009; Eschbach et al., 2005, 2004; Ostir et al., 2003; Patel et al., 2003; Reyes-Ortiz et al., 2009; Kandula et al., 2009; Walton, 2009). Segregated neighborhoods may also provide unique protections to more recently-arrived ethnic groups by buffering the stress of acculturation and providing access to country-of-origin foods (Lieberson, 1961; Duany, 1998).

The aim of this paper is to increase understanding of the segregation-health relationship by examining preterm birth risk in ethnically dense areas across multiple, often understudied, ethnic groups. Preterm birth, or birth before the 37th week of gestation, is an outcome of particular public health relevance because it is an important cause of infant mortality, leads to a variety of morbidities and learning impairments in children and adults, and is the largest contributor to the two-fold black-white disparity in infant death (Berkowitz and Papiernik, 1993; Fiscella, 2004; Hogue and Hargraves, 1995). Understanding of the etiology of preterm birth remains vague, but mounting evidence suggests that stress may play a particularly important role, either by triggering hormones related to labor initiation or through an inflammatory pathway provoked by immune suppression and infection (Culhane and Elo, 2005; Rowley, 1994; Hogue and Bremner, 2005; Wadhwa et al., 2001a; Wadhwa et al., 2001b; Goldenberg et al., 2008). Several studies have documented a correlation between preterm birth and stressful life experiences (Dole et al., 2004; Lu and Chen, 2004; Collins et al., 2000; Rosenberg et al., 2002), self-reported stress (Rini et al., 1999), and stressful neighborhood environments (Messer et al., 2006a). These studies suggest that preterm birth may be sensitive to the material and psychosocial environments that vary with neighborhood ethnic density.

We used New York City birth records to estimate the risk of preterm birth associated with neighborhood ethnic density. Studies of ethnic density effects for Hispanics and Asians 
remain rare; to address this gap in the literature, we included Spanish Caribbeans, Central Americans (plus Mexicans), South American Hispanics, East Asians, and South Asians in our analyses, in addition to non-Hispanic whites and blacks. Furthermore, most studies to date have relied on administrative units (e.g. census tracts) alone to define neighborhood ethnic density (so-called "aspatial measures"). Because of concerns that aspatial measures may mis-characterize the geographic distributions of ethnic groups (Reardon, 2006), we represented the ethnic composition of each mother's neighborhood with a spatial measure, "proximity-weighted ethnic density," which allows the ethnic composition of the areas surrounding the mother's residence to influence her estimated exposure in proportion to their distance from her (Reardon and Firebaugh, 2002; Reardon et al., 2008).

\section{Methods}

\subsection{Data Sources and management}

New York City birth records from January 1, 1995 through December 31, 2003 provided outcome (gestational age), ethnicity, and individual-level covariate data on all singleton births occurring to residents of New York City over the nine-year period $(N=1,052,576)$. The birth records were geocoded and each observation was assigned a 1990 or 2000 census tract number (depending on the year of birth) by the New York City Department of Health and Mental Hygiene. We excluded births missing gestational age information $(N=6418)$. We also excluded births if they were missing census tract or county information $(N=108,433)$, or were assigned to non-existent $(N=1812)$, ambiguous $(N=62)$, or unpopulated $(N=28)$ census tracts. Preterm birth rates were similar across observations with and without complete census tract information.

We defined seven ethnic group categories (non-Hispanic white, non-Hispanic black, Spanish Caribbean, Central American plus Mexican, South American Hispanic, East Asian, and South Asian) from the self-reported race and ethnic origin variables available in the birth records (Fig. 1). Births without the race or ethnic origin information necessary to create maternal ethnic group categories $(N=8801)$ were excluded. Births to women with nonHispanic ethnic origins that were not white, black, East Asian, or South Asian $(N=13,923)$ or to women who reported a Hispanic ethnic origin not in the Spanish Caribbean, Central America, or South America $(N=25,212)$ were not included in the study. These exclusions left 887,887 observations for the analysis.

The NYC Department of Health and Mental Hygiene assigned 1990 tract numbers to births occurring in 1995-1999 and 2000 tract numbers to births occurring in 2000-2003. Between the two censuses, the Census Bureau split some 1990 census tracts to create two 2000 census tracts, and merged some 1990 tract pairs to create single 2000 tracts (New York City Department of City Planning. Table G-1: New York City 1990 Census Tracts with Boundary/Number Changes for 2000 Census, 2001). To create consistent tract numbers over time, we gave 1990 tracts that were merged in 2000 their corresponding 2000 tract numbers. Likewise, we gave 2000 tracts that had split from 1990 tracts their "parent" 1990 tract numbers. After updating, there were 2156 unique tracts containing births included in the analysis.

We obtained total and ethnic group population counts in the 2217 tracts contained in the five counties of New York City from Summary File 1 of the 2000 US Census and area-level covariates from Summary File 3. In order to match the birth records, we merged 15 year2000 tract pairs to re-create the 151990 tracts from which they were split, leaving 2202 unique tracts in the census data. Census tracts that were not found in the birth records consisted primarily of low-population tracts and Tract 1 in the Bronx, corresponding to Riker's Island Prison. 


\subsection{Variables and variable construction}

We defined the outcome, preterm birth, as a live singleton birth at greater than 20 but less than 37 completed weeks of gestation using the clinical estimate of gestational age (Berkowitz and Papiernik, 1993).

We defined the exposure, neighborhood ethnic density, as the percentage of the population in a woman's area of residence with a given ethnic identity. For non-Hispanic white and black mothers, respectively, we used non-Hispanic white and black densities as the exposures. For Spanish Caribbean, Central American, and South American mothers, we defined the exposure as the neighborhood density of Hispanics, and for East and South Asian mothers we defined the exposure as Asian density. While region-specific ethnic densities (e.g. density of Central Americans) were available from the census data, and were theoretically preferable, they included a large amount of missing data due to smallpopulation data suppression (US Census Bureau. Summary File 4: Technical Documentation, 2000). We did, however, conduct a secondary analysis using the regionspecific ethnic densities for comparison.

Following previous authors (Reardon and Firebaugh, 2002; Reardon et al., 2008), we assumed that the areas nearest a woman contributed most to her experience of neighborhood-level ethnic density. We allowed populations farther away to influence her estimated exposure as well, but this influence decreased in proportion to distance. Because they were the smallest unit available in the birth records, we used census tracts to locate the women geographically, and used the distances between approximate census tract centers (centroids) to estimate the distance from each woman's residence to other populations. New York City census tracts are geographically small, with a median area of 0.18 square kilometers, allowing us to locate populations fairly precisely. We positioned centroids using a center-of-mass generator (Jenness Enterprises: Polygon Center of Mass), which estimates the geographically-weighted center of each tract, and computed between-centroid distances in ArcGIS (ESRI).

We calculated the "proximity-weighted ethnic density" (Reardon and Firebaugh, 2002) $\left(\prod_{J M}\right)$ for a woman belonging to ethnic group $M$ and residing in census tract $J$ by multiplying the population count of ethnic group $N$ in each census tract $K\left(x_{K N}\right)$ by a weight $\left(p_{J K}\right)$ that represents the proximity of tracts $J$ and $K$. We summed these weighted ethnic populations and divided the sums by total census tract populations $\left(x_{K}\right)$ that were weighted in the identical manner. This produced a weighted "percent" as shown below:

$$
\prod_{J M}=\frac{\sum_{K}\left(x_{K N} \times p_{J K}\right)}{\sum_{K}\left(x_{K} \times p_{J K}\right)}
$$

The proximity weight $\left(p_{J K}\right)$, a "biweight kernel", allows census tract $K$ 's influence to decay in an approximately Gaussian manner with its distance from census tract $J$ (Lee et al., 2006):

$$
p_{J K}=\left(1-\left(\frac{d_{J K}}{r}\right)^{2}\right)^{2} \quad \text { if } d_{J K}<r, \text { else } p_{J K}=0
$$

where $d_{J K}$ is the distance between census tracts $J$ and $K$. Note that if $J=K$, then $d_{J K}=0$ and $p_{J K}=1$; that is, a census tract's own ethnic composition will have maximal influence on the estimated exposure of the residents of that census tract. The variable $r$ is the distance from 
census tract $J$ beyond which there is no influence on $J$ 's estimated ethnic density. The value of the radius was chosen based on the hypothesized area thought to meaningfully affect the environment of those living in census tract $J$. Lee and colleagues suggest a radius of $500 \mathrm{~m}$ to approximate residential areas accessible by foot (Lee et al., 2006), which we considered to be an appropriate neighborhood definition for a densely populated urban area such as New York City. Because there is no generally accepted threshold at which ethnic density is thought to be most influential, we dichotomized proximity-weighted ethnic density at $25 \%$ in order to allow an adequate number of births in both exposed and unexposed categories across ethnic groups. Two sensitivity analyses were conducted, one with ethnic densities dichotomized at $20 \%$ to ensure that results were not driven by random variability at one cutpoint, and a second with ethnic densities coded as continuous variables with squared terms allowing for exploration of non-linearities in the ethnic density-preterm birth association.

We included the following covariates in the adjusted models: maternal age (indicators for < $20,20-34$, and 35+ years), education taking age into account (indicators for $<12$ years and < 20 years of age, $<12$ years and 20+ years of age, 12 years, $13-15$ years, and $16+$ years), nativity (US- or foreign-born), parity (indicators for 1, 2-5, and 6+ previous births), tobacco use (smoker or nonsmoker), prepregnancy weight (indicators for $<125,125-150$, and $>150$ pounds), prenatal care received in first 120 days of gestation (yes or no), and payment type (indicators for private insurance, Medicaid, or out-of-pocket).

In addition, we included two neighborhood-level covariates, residential stability (percent of the neighborhood population residing in the same house from 1995 to 2000) and neighborhood deprivation. Neighborhood deprivation was represented using a standardized index arising from 17 tract-level census variables (\% of the population with less than a highschool education, $\%$ unemployed, $\%$ males not in work force, $\%$ crowding, $\%$ renteroccupied units, $\%$ male professionals, $\%$ female professionals, $\%$ males in management, $\%$ females in management, \% poverty, $\%$ female-headed household with children, $\%$ households with $<\$ 30,000 /$ year, \% households on public assistance, \% households with no car, median household income, median income of individuals with earnings, median value of owner-occupied units) that were summarized using principle components analysis as previously described (Messer et al., 2006b). Using this index allowed us to adjust for multiple highly correlated dimensions of neighborhood deprivation in the model without creating problems of multicollinearity. Both residential stability and the component variables of the neighborhood deprivation index were proximity-weighted in the same manner as ethnic density and dichotomized at the overall median. Adjustment for continuous neighborhood deprivation produced similar results.

\subsection{Data analysis}

We used logistic regression to model the relationship between preterm birth and dichotomized proximity-weighted ethnic density for each ethnic group separately. The Huber-White "sandwich" variance estimator was employed to account for clustering at the census tract level (Williams, 2000). The coefficients from these marginal models closely approximated the results from random-intercept models, for which the estimated intracluster correlation coefficients were very small (all $<0.02$ ); we therefore chose to use marginal models. Recent articles have also argued that results from marginal models are more appropriate for public health inference because they estimate an average effect for the entire population rather than for the population of a single neighborhood (Hubbard et al., 2010).

We employed the following modeling strategy for all ethnic groups. First, we modeled the log odds of preterm birth as a function of ethnic density alone to estimate the crude exposure-outcome association. Second, models were adjusted for all covariates. Third, we 
re-ran adjusted models without the two most frequently missing covariates: prenatal care and prepregnancy weight. Almost 20\% of observations were missing one or more of these variables. We conducted a change-in-estimate analysis to assess the extent of confounding incurred by their exclusion; we considered a change in the odds ratio of less than $10 \%$ small enough to warrant omitting them to increase precision and generalizability (Mickey and Greenland, 1989). Fourth, we stratified the models by neighborhood deprivation, since the psychosocial correlates of segregation may have a different association with preterm birth depending on the resource environment that is also present (Pickett et al., 2005; Phillips et al., 2009). Finally, we computed crude, adjusted, and stratified risk differences (RDs) from the logistic model regression coefficients, with US-born women aged 20-34 who were highschool educated, had 2-5 previous live births, received early prenatal care, were on Medicaid, and resided in a more stable and poorer neighborhood as the reference risk group. Risk differences provide an estimate of the number of preterm births attributable to (or prevented by) residence in ethnic enclaves (assuming the modeled associations are correct and causal), and are therefore particularly informative for public health and policy applications.

We conducted several sensitivity analyses to assess potential changes in the results when using different population and variable specifications. First, we re-ran the models with ethnic density dichotomized at $20 \%$ rather than $25 \%$. Second, we used linked hospital discharge diagnosis and procedure codes to identify and exclude medically indicated preterm births (births subsequent to any surgical or medical induction of labor and births subsequent to pre-labor cesarean sections) in order to obtain results specific to spontaneous preterm birth. Third, we restricted analyses to primiparous women, to remove any influence of repeat births to the same mother over the nine-year study period. Fourth, were-ran models among mothers whose ethnic identity matched the father's ethnic identity, since the father's ethnic affiliation may influence the mother's experience of ethnic density in her neighborhood. Finally, we re-ran models among foreign-born women only.

We also re-ran analyses with region-specific ethnic densities (e.g. Central American density rather than Hispanic density), dichotomized at $15 \%$ to accommodate the lower average density of regional populations.

To provide a more complete picture of the shape of the relationship between ethnic density and preterm birth, we plotted predicted probabilities of preterm birth estimated from adjusted models with ethnic density coded continuously with a squared term (to allow for non-linearities). We used these predicted probabilities to calculate risk differences for 30$10 \%$ and $50-10 \%$ ethnic density contrasts.

\section{Results}

The majority of the 887,887 births included in the analysis occurred to non-Hispanic white, non-Hispanic black, or Spanish Caribbean women (Tables 1a and 1b), reflecting the ethnic distribution of the city as a whole. The proportion of births to Central Americans, South Americans, and South Asians was greater than their proportion in the general population, indicating high fertility.

East Asians had the lowest risk of preterm birth of all the ethnic groups, followed closely by non-Hispanic whites. Non-Hispanic blacks had by far the highest risk (Tables 1a and 1b). Non-Hispanic blacks did not, however, have the least favorable distribution of covariate risk factors, as they were more likely than Spanish Caribbeans, Central Americans, and South Americans to have education beyond a high school degree, were less likely to be on Medicaid than any other group except whites, and were more likely than Spanish Caribbeans or East Asians to have early prenatal care. 
The degree of ethnic density commonly experienced in the maternal neighborhood varied drastically by ethnic group, with non-Hispanic white and black births occurring largely to women residing in majority white or black neighborhoods, respectively (Fig. 2), but East and South Asian births occurring mostly to women in neighborhoods with only a small proportion of other Asians. The Hispanic groups fell in between, with Spanish Caribbean births more likely to occur in highly Hispanic neighborhoods than either Central or South American births. These ethnic density differences reflect the relative size of the ethnic populations, but also follow documented national and historical trends in which blacks and whites are highly segregated from one another, while Asians tend to integrate into white neighborhoods and Hispanics fall somewhere in between (Fischer et al., 2004; Massey and Denton, 1987; Massey, 1981). The geographic distribution of these groups is shown in Fig. 3 , which illustrates the high degree of clustering by ethnicity.

Crude changes in preterm birth risk associated with maternal residence in an ethnic neighborhood (> 25\% ethnic density) versus a less ethnically dense neighborhood ranged from -17.0 per 1000 (95\% CI: $-20.9,-13.1)$ for white women, indicating a substantial protective effect of own-group density, to 9.5 per 1000 (95\% CI: 6.0, 13.1) for black women, indicating increased risk associated with residence in a black neighborhood. The Hispanic and Asian group estimates fell between those for whites and blacks. Controlling for covariates moved the estimates toward the null for all groups except South Americans (Table 2, Fig. 4). When adjusted, the risk difference was -15.0 per $1000(-18.5,-11.4)$ among whites and 6.4 per 1000 (95\% CI: 2.8, 9.9) among blacks.

The two most frequently missing variables - prenatal care and prepregnancy weight-were not included in the final adjusted models, because the change in the odds ratio resulting from their exclusion was 5\% or less in all groups. Fully adjusted risk differences (computed with these two variables retained) are presented in Table 1 of the Online Appendix for comparison; estimates from the fully adjusted models were farther from the null for all groups except whites and East Asians. These results should be treated with some caution, however, as they are based on analyses missing over $20 \%$ of the observations.

Changes in the risk differences across neighborhood deprivation strata exceeded 5 per 1000 for non-Hispanic white, Central American, South American, and South Asian groups. Interactions between ethnic density and neighborhood deprivation were statistically significant $(p<0.05)$ for non-Hispanic whites and Central Americans. Risk differences for white women in richer and poorer neighborhoods were -8.3 (95\% CI: $-14.4,-2.2)$ per 1000 and -20.0 (95\% CI: $-25.9,-14.1)$ per 1000, respectively. For Central Americans the risk differences per 1000 were 2.1 (95\% CI: -4.2, 8.5) and -9.6 (95\% CI: -18.5, -0.8), for South Americans they were 3.2 (95\% CI: $-3.5,9.9)$ and -2.8 (95\% CI: $-19.3,13.6)$, and for South Asians they were -4.9 (95\% CI: $-11.9,2.1)$ and -15.3 (95\% CI: $-32.0,1.4)$ in richer and poorer neighborhoods, respectively. For all the groups, with the exception of non-Hispanic blacks, the RD was lower when estimated in poorer neighborhoods (Table 2, Fig. 5), but many of these estimates were quite imprecise.

We re-ran stratified models for the white, Hispanic, and Asian groups with non-Hispanic black density included, to explore the possibility that differences in estimates across neighborhood deprivation categories are driven by differences in the "out-group" ethnic composition. (For example, white women residing in non-white neighborhoods are more likely to be living with Asians if their neighborhood is wealthy and blacks if their neighborhood is poor.) Controlling for non-Hispanic black density in the models did not, however, change the overall pattern of the results, although some estimates moved slightly toward the null (Online Appendix Table 2). 
The overall pattern of findings remained largely unchanged in additional sensitivity analyses (Table 3 and Fig. 1 of the Online Appendix). For the smaller groups (e.g. South Americans), restricting to primiparous women shifted the estimates more substantially, but the level of imprecision was also increased so it was difficult to say whether this was a meaningful change. When the father's ethnic identity matched the mother's, the effect of ethnic density appeared to be less protective among white mothers but more protective among Spanish Caribbean mothers; however, paternal ethnicity information was missing for about $20 \%$ of the births, so these results should be interpreted with caution.

When we used region-specific ethnic densities as the exposures, the Central American and South Asian estimates were moved close to the null, but these estimates were obtained from models with $12.5 \%$ of Central American observations and $18.4 \%$ of South Asian observations excluded due to missing exposure values (two sets of results, one with missing data excluded and the other with missing data assumed to be zero are presented in the Online Appendix Table 4). The null value for the Central American estimate appears to arise at least in part from a scarcity of women in wealthy Central American tracts ( $N=93)$, such that it was not possible to adequately control for neighborhood deprivation.

Predicted probabilities estimated using continuous ethnic density, with a squared term to allow for deviations from linearity, suggest that the relationship between ethnic density and preterm birth may be non-linear in some groups (Online Appendix Fig.2 and Table 5). In particular, black preterm birth risks in wealthier neighborhoods appear to increase with ethnic density until ethnic density reaches around 50\%, then level off and possibly decrease slightly. Overall, deviations from linearity were small, however, and indicate that the contrast between $>25 \%$ and $\leq 25 \%$ ethnic density from the main analysis are a useful summary of the ethnic density—preterm birth relationship across groups.

\section{Discussion}

Our study results suggest that higher ethnic density is associated with poorer birth outcomes among non-Hispanic black women, consistent with some (Grady, 2006; Morenoff, 2003; Ellen, 2000) (Baker and Hellerstedt, 2006; Osypuk and Acevedo-Garcia, 2008) but not all (Roberts, 1997) previous research. We found a substantial reduction in preterm birth risk among white women living in whiter neighborhoods, and among most Hispanic and Asian groups, the associations between ethnic density and preterm birth appeared to be null or slightly protective.

A growing body of evidence suggests that ethnic density may positively influence an area's social environment (Pickett and Wilkinson, 2008; Putnam, 2007). Recent experimental research suggests, for example, that the capacity for collective action is influenced by norms of reciprocity that encourage collaboration between members of the same ethnic group and discourage cross-ethnic cooperation (Habyarimana et al., 2009), making ethnic density a potentially important determinant of social organization. Evidence of variation in ethnic density effects that we observe here suggests that hypothesized benefits of ethnic density may accrue more to some ethnic groups than others, however. For example, the difference in ethnic density responses between non-Hispanic blacks and Hispanics, despite similar levels of poverty, may result from unique protections in Hispanic neighborhoods (such as healthful food environments) that are not available to non-Hispanic blacks.

Alternatively, unmeasured differences in neighborhood resources may influence ethnic density effects. In particular, a long history of racial oppression and chronic underinvestment in black neighborhoods may make black density a marker of entrenched and concentrated neighborhood poverty that our neighborhood deprivation measures do not fully 
capture. The historical context in which neighborhoods have often been formed could, in addition, influence the psychosocial well-being of their residents; years of racially-based barriers to geographic mobility may, for instance, create a sense of powerlessness among residents of black neighborhoods. It is also possible that the associations between ethnic density and preterm birth differ because non-Hispanic black women in New York City are more likely to be US-born - and may thus have spent more time in their neighborhoodsthan the largely immigrant Hispanic and Asian groups. Although we adjusted for maternal immigrant status, we had no information on timing of neighborhood residence, so we could not account for differences in exposure duration.

Stratifying by neighborhood deprivation suggested that the influence of ethnic density on health may be modified by the material environment. When estimated within poorer neighborhoods, risk differences for all groups (with the notable exception of non-Hispanic blacks) indicated a protective effect of residence in an ethnic neighborhood, although some point estimates were close to null. Among whites and South Asians, particularly, the risk reductions in poorer neighborhoods were sizeable and differed substantially from estimates in wealthier areas. Scarcity of health-promoting resources in poorer neighborhoods may increase the relative importance of psychosocial benefits arising from a shared ethnic or cultural identity. This possibility could not be examined with the available data, however.

Census data suppression for small population groups limited our ability to estimate regionspecific ethnic density effects. Region-specific ethnic densities may be more meaningful for the social experience of a woman in a given neighborhood than densities based on broader ethnic definitions. While we provide supplemental estimates of region-specific ethnic density effects, the imprecision of the results and the high level of exposure missingness makes these estimates difficult to interpret. The spatial patterning of births suggests that region-specific groups live in distinct areas of the city, and thus broader ethnic densities may closely approximate the region-specific ethnic density that is predominant in a given neighborhood; for example, because of self-segregation by region, Hispanic density may be a reasonable proxy for Central American density when estimated in a Central American woman's neighborhood. Nonetheless, robust measures of region-or even country-specific densities might reveal additional variation of effects, and future research in this area might consider examining groups, such as Puerto Ricans and Chinese, with potentially sufficient numbers to support this level of nuance.

Recent publications have highlighted the problem of investigating the independent effects of neighborhood economic and ethnic segregation (Oakes, 2006; Messer et al., 2010), since these two characteristics tend to be highly correlated (Sampson et al., 2008). An examination of the underlying distribution of the exposure and covariates within neighborhood deprivation strata revealed few cells with a glaring lack of data. Some uncontrolled confounding is, of course, still possible due to heterogeneity within covariate categories. The difficulty of disentangling the independent influences on health of the neighborhoods themselves from the characteristics that cause individuals to select into the neighborhoods in the first place also remains a challenge (Oakes, 2004).

Despite its limitations, our study has two key strengths. First, we included a large number of ethnicities, including under-studied Hispanic and Asian groups, enabled by the unique diversity of the New York City population. In addition, we employed a spatial measure of neighborhood-level ethnic density to address the documented limitations of non-spatial measures. The radius, 500 meters, represents a walkable distance around the residential area (Lee et al., 2006), and was chosen as a theoretically appropriate neighborhood approximation for a population-dense urban area like New York City. 
The results of this analysis suggest that the balance of beneficial and harmful material and psychosocial correlates of segregation may differ across ethnic groups. Segregation appeared to benefit whites and harm blacks in this study, perhaps reflecting the long history of unequal resource distribution between blacks and whites of which segregation is a cause, consequence, and marker. The more recently-arrived groups that are largely outside this history had somewhat more limited responses, but results suggested a protective effect, especially in poorer neighborhoods. The data used for this analysis prevented investigation of hypothesized pathways between ethnic density and health, but suggest that historical context may be important for understanding the associations between neighborhoods and health; the findings provide a basis future research exploring these mechanisms in greater depth.

\section{Supplementary Material}

Refer to Web version on PubMed Central for supplementary material.

\section{References}

Acevedo-Garcia D. Zip code-level risk factors for tuberculosis: neighborhood environment and residential segregation in New Jersey, 1985-1992. Am J Public Health. 2001; 91:734-741. [PubMed: 11344881]

Baker AN, Hellerstedt WL. Residential racial concentration and birth outcomes by nativity: do neighbors matter? J Natl Med Assoc. 2006; 98:172-180. [PubMed: 16708503]

Bell JF, Zimmerman FJ, Almgren GR, Mayer JD, Huebner CE. Birth outcomes among urban AfricanAmerican women: a multilevel analysis of the role of racial residential segregation. Soc Sci Med. 2006; 63:3030-3045. [PubMed: 16997438]

Berkowitz GS, Papiernik E. Epidemiology of preterm birth. Epidemiol Rev. 1993; 15:414-443. [PubMed: 8174665]

Bledsoe T, Welch S, Sigelman L, Combs M. Residential Context and Racial Solidarity among African Americans. Am J Pol Sci. 1995; 39:434-458.

Chang VW. Racial residential segregation and weight status among US adults. Soc Sci Med. 2006; 63:1289-1303. [PubMed: 16707199]

Collins CA, Williams DR. Segregation and Mortality: the Deadly Effects of Racism? Soc Forum. $1999 ; 14: 495-523$.

Collins JW Jr, David RJ, Symons R, Handler A, Wall SN, Dwyer L. Low-income African-American mothers' perception of exposure to racial discrimination and infant birth weight. Epidemiology. 2000; 11:337-339. [PubMed: 10784254]

Cooper RS, Kennelly JF, Durazo-Arvizu R, Oh HJ, Kaplan G, Lynch J. Relationship between premature mortality and socioeconomic factors in black and white populations of US metropolitan areas. Public Health Rep. 2001; 116:464-473. [PubMed: 12042610]

Culhane JF, Elo IT. Neighborhood context and reproductive health. Am J Obstet Gynecol. 2005; 192:S22-S29. [PubMed: 15891708]

Cutler DM, Glaeser EL. Are ghettos good or bad? Q J Econ. 1997; 112:827-872.

Dole N, Savitz DA, Siega-Riz AM, Hertz-Picciotto I, Mcmahon MJ, Buekens P. Psychosocial factors and preterm birth among African American and White women in central North Carolina. Am J Public Health. 2004; 94:1358-1365. [PubMed: 15284044]

Duany J. Reconstructing Racial Identity: ethnicity, Color, and Class among Dominicans in the United States and Puerto Rico. Lat Am Perspect. 1998; 25:147-172.

Ellen, IG. Brookings Wharton Pap Urban Affairs. 2000. Is segregation bad for your health? The case of low birth weight; p. 203-238.

Eschbach K, Mahnken JD, Goodwin JS. Neighborhood composition and incidence of cancer among Hispanics in the United States. Cancer. 2005; 103:1036-1044. [PubMed: 15672387] 
Eschbach K, Ostir GV, Patel KV, Markides KS, Goodwin JS. Neighborhood context and mortality among older Mexican Americans: is there a barrio advantage? Am J Public Health. 2004; 94:1807-1812. [PubMed: 15451754]

Fang J, Madhavan S, Bosworth W, Alderman MH. Residential segregation and mortality in New York City. Soc Sci Med. 1998; 47:469-476. [PubMed: 9680230]

Fiscella K. Racial disparity in infant and maternal mortality: confluence of infection, and microvascular dysfunction. Matern Child Health J. 2004; 8:45-54. [PubMed: 15198171]

Fischer CS, Stockmayer G, Stiles J, Hout M. Distinguishing the Geographic Levels and Social Dimensions of U.S. Metropolitan Segregation, 1960-2000. Demography. 2004; 41:37-59. [PubMed: 15074124]

Fong E, Shibuya K. Multiethnic cities in North America. Annu Rev Sociol. 2005; 31:285-304.

Goldenberg RL, Culhane JF, Iams JD, Romero R. Epidemiology and causes of preterm birth. Lancet. 2008; 371:75-84. [PubMed: 18177778]

Gorman BK. Racial and ethnic variation in low birthweight in the United States: individual and contextual determinants. Health Place. 1999; 5:195-207. [PubMed: 10984575]

Grady SC. Racial disparities in low birthweight and the contribution of residential segregation: a multilevel analysis. Soc Sci Med. 2006; 63:3013-3029. [PubMed: 16996670]

Guest AM, Almgren G, Hussey JM. The Ecology of Race and Socioeconomic Distress: infant and Working-Age Mortality in Chicago. Demography. 1998; 35:23-34. [PubMed: 9512907]

Habyarimana, J.; Humphreys, M.; Posner, DN.; Weinstein, JM. Coethnicity: Diversity and the Dilemmas of Collective Action. Russell Sage Foundation; New York, NY: 2009.

Hart KD, Kunitz SJ, Sell RR, Mukamel DB. Metropolitan governance, residential segregation, and mortality among African Americans. Am J Public Health. 1998; 88:434-438. [PubMed: 9518976]

Hogue CJ, Bremner JD. Stress model for research into preterm delivery among black women. Am J Obstet Gynecol. 2005; 192:S47-S55. [PubMed: 15891712]

Hogue CJ, Hargraves MA. Preterm birth in the African-American community. Semin Perinatol. 1995; 19:255-262. [PubMed: 8560290]

Hubbard AE, Ahern J, Fleischer NL, Van Der Laan M, Lippman SA, Jewell N, Bruckner T, Satariano WA. To GEE or Not to GEE: comparing Population Average and Mixed Models for Estimating the Associations Between Neighborhood Risk Factors and Health. Epidemiology. 2010; 21:467474. [PubMed: 20220526]

Huie SAB, Hummer RA, Rogers RG. Individual and Contextual Risks of Death among Race and Ethnic Groups in the United States. J Health Soc Behav. 2002; 43:359-381. [PubMed: 12467258]

Hutchinson JF, Rodriguez N, Hagan J. Community Life: African Americans in Multiethnic Residential Areas. J Black Stud. 1996; 27:201-223.

Inagami S, Borrell LN, Wong MD, Fang J, Shapiro MF, Asch SM. Residential segregation and Latino, black and white mortality in New York City. J Urban Health. 2006; 83:406-420. [PubMed: 16739044]

Jackson SA, Anderson RT, Johnson NJ, Sorlie PD. The relation of residential segregation to all-cause mortality: a study in black and white. Am J Public Health. 2000; 90:615-617. [PubMed: 10754978]

Jenness Enterprises: Polygon Center of Mass. [Accessed 9/20/2010] http://www.jennessent.com/ arcview/centermass.htm

Jenny AM, Schoendorf KC, Parker JD. The association between community context and mortality among Mexican-American infants. Ethn Dis. 2001; 11:722-731. [PubMed: 11763295]

Kandula NR, Wen M, Jacobs EA, Lauderdale DS. Association between neighborhood context and smoking prevalence among Asian Americans. Am J Public Health. 2009; 99:885-892. [PubMed: 19299683]

Laveist TA. Linking residential segregation to the infant-mortality race disparity in US cities. Sociol Soc Res. 1989; 73:90-94.

LeClere FB, Rogers RG, Peters KD. Ethnicity and mortality in the United States: individual and community correlates. Soc Forces. 1997; 76:169-198. 
Lee BA, Reardon SF, Firebaugh G, Farell CR, Matthews SA, O'sullivan D. Beyond the Census Tract: patterns and Determinants of Racial Residential Segregation at Multiple Scales. Am Soc Rev. 2006; 73:766-791.

Lieberson S. The Impact of Residential Segregation on Ethnic Assimilation. Soc Forces. 1961; 40:5257.

Lu MC, Chen B. Racial and ethnic disparities in preterm birth: the role of stressful life events. Am J Obstet Gynecol. 2004; 191:691-699. [PubMed: 15467527]

Lynch J. Income inequality and health: expanding the debate. Soc Sci Med. 2000; 51:1001-1005. discussion 1009-10. [PubMed: 11005387]

Mason SM, Messer LC, Laraia BA, Mendola P. Segregation and preterm birth: the effects of neighborhood racial composition in North Carolina. Health Place. 2009; 15:1-9. [PubMed: 18359264]

Massey DS. Social Class and Ethnic Segregation: a Reconsideration of Methods and Conclusions. Am Soc Rev. 1981; 46:641-650.

Massey DS. American Apartheid: segregation and the Making of the Underclass. Am J Sociol. 1990; 96:329-357.

Massey DS, Denton NA. Trends in the Residential Segregation of Blacks, Hispanics, and Asians: 1970-1980. Am Soc Rev. 1987; 52:802-825.

Massey DS, Denton NA. Hypersegregation in U.S. metropolitan areas: Black and Hispanic segregation along five dimensions. Demography. 1989; 26:373-391. [PubMed: 2792476]

McCord C, Freeman HP. Excess mortality in Harlem. New Engl J Med. 1990; 322:173-177. [PubMed: 2294438]

Messer LC, Kaufman JS, Dole N, Savitz DA, Laraia BA. Neighborhood crime, deprivation, and preterm birth. Ann Epidemiol. 2006a; 16:455-462. [PubMed: 16290179]

Messer LC, Laraia BA, Kaufman JS, Eyster J, Holzman C, Culhane J, Elo I, Burke JG, O'campo P. The development of a standardized neighborhood deprivation index. J Urban Health. 2006b; 83:1041-1062. [PubMed: 17031568]

Messer LC, Oakes JM, Mason S. Effects of socioeconomic and racial residential segregation on preterm birth: a cautionary tale of structural confounding. Am J Epidemiol. 2010; 171:664-673. [PubMed: 20139129]

Mickey RM, Greenland S. The impact of confounder selection criteria on effect estimation. Am J Epidemiol. 1989; 129:125-137. [PubMed: 2910056]

Morello-Frosch R, Jesdale BM. Separate and unequal: residential segregation and estimated cancer risks associated with ambient air toxics in U.S. metropolitan areas. Environ Health Perspect. 2006; 114:386-393. [PubMed: 16507462]

Morenoff JD. Neighborhood Mechanisms and the Spatial Dynamics of Birth Weight. Am J Sociol. 2003; 108:976-1017. [PubMed: 14560732]

New York City Department of City Planning. [Accessed 9/20/2010] Table G-1: New York City 1990 Census Tracts with Boundary/Number Changes for 2000 Census. 2001. http://www.nyc.gov/html/ dcp/pdf/census/g1.pdf

Oakes JM. The (mis)estimation of neighborhood effects: causal inference for a practicable social epidemiology. Soc Sci Med. 2004; 58:1929-1952. [PubMed: 15020009]

Oakes JM. Commentary: advancing neighbourhood-effects research-selection, inferential support, and structural confounding. Int J Epidemiol. 2006; 35:643-647. [PubMed: 16556642]

Ostir GV, Eschbach K, Markides KS, Goodwin JS. Neighbourhood composition and depressive symptoms among older Mexican Americans. J Epidemiol Commun Health. 2003; 57:987-992.

Osypuk TL, Acevedo-Garcia D. Are racial disparities in preterm birth larger in hypersegregated areas? Am J Epidemiol. 2008; 167:1295-1304. [PubMed: 18367470]

Osypuk TL, Diez-Roux AV, Hadley C, Kandula NR. Are immigrant enclaves healthy places to live? The Multi-ethnic Study of Atherosclerosis. Soc Sci Med. 2009; 69:110-120. [PubMed: 19427731]

Patel KV, Eschbach K, Rudkin LL, Peek MK, Markides KS. Neighborhood context and self-rated health in older Mexican Americans. Ann Epidemiol. 2003; 13:620-628. [PubMed: 14732301] 
Peterson RD, Krivo LJ. Racial Segregation, the Concentration of Disadvantage, and Black and White Homicide Victimization. Soc Forum. 1999; 14:465-493.

Phillips GS, Wise LA, Rich-Edwards JW, Stampfer MJ, Rosenberg L. Income incongruity, relative household income, and preterm birth in the Black Women's Health Study. Soc Sci Med. 2009; 68:2122-2128. [PubMed: 19394740]

Pickett KE, Collins JW Jr, Masi CM, Wilkinson RG. The effects of racial density and income incongruity on pregnancy outcomes. Soc Sci Med. 2005; 60:2229-2238. [PubMed: 15748671]

Pickett KE, Wilkinson RG. People like us: ethnic group density effects on health. Ethn Health. 2008; 13:321-334. [PubMed: 18701992]

Polednak AP. Black-white differences in infant mortality in 38 standard metropolitan statistical areas. Am J Public Health. 1991; 81:1480-1482. [PubMed: 1951808]

Polednak AP. Poverty, residential segregation, and black/white mortality ratios in urban areas. J Health Care Poor Underserved. 1993; 4:363-373. [PubMed: 8260570]

Polednak AP. Trends in US urban black infant mortality, by degree of residential segregation. Am J Public Health. 1996; 86:723-726. [PubMed: 8629726]

Putnam RD. E Pluribus Unum: diversity and community in the twenty-first century. The 2006 Johan Skytte Prize Lecture. Scand Polit Stud. 2007; 30:137-174.

Reardon, SF. A conceptual framework for measuring segregation and its association with population outcomes. In: Oakes, MJ.; Kaufman, JS., editors. Methods in Social Epidemiology. Jossey-Bass Publishing; 2006.

Reardon SF, Firebaugh G. Response: segregation and Social Distance: a Generalized Approach to Segregation Measurement. Sociol Methodol. 2002; 32:85-101.

Reardon SF, Matthews SA, O'sullivan D, Lee BA, Firebaugh G, Farell CR, Bischoff K. The Geographic Scale of Metropolitan Racial Segregation. Demography. 2008; 45:489-514. [PubMed: 18939658]

Reyes-Ortiz CA, Ju H, Eschbach K, Kuo YF, Goodwin JS. Neighbourhood ethnic composition and diet among Mexican-Americans. Public Health Nutr. 2009:1-9. [PubMed: 19087373]

Rini CK, Dunkel-Schetter C, Wadhwa PD, Sandman CA. Psychological adaptation and birth outcomes: the role of personal resources, stress, and sociocultural context in pregnancy. Health Psychol. 1999; 18:333-345. [PubMed: 10431934]

Roberts EM. Neighborhood social environments and the distribution of low birthweight in Chicago. Am J Public Health. 1997; 87:597-603. [PubMed: 9146438]

Rosenberg L, Palmer JR, Wise LA, Horton NJ, Corwin MJ. Perceptions of racial discrimination and the risk of preterm birth. Epidemiology. 2002; 13:646-652. [PubMed: 12410005]

Rowley DL. Research issues in the study of very low birthweight and preterm delivery among African-American women. J Natl Med Assoc. 1994; 86:761-764. [PubMed: 7807560]

Sampson R, Sharkey P, Raudenbush S. Durable effects of concentrated disadvantage on verbal ability among African-American children. Proc Natl Acad Sci. 2008; 105:845-852. [PubMed: 18093915]

Sampson RJ, Groves WB. Community structure and crime: testing social-disorganization theory. Am J Sociol. 1989; 94:774-802.

Subramanian SV, Acevedo-Garcia D, Osypuk TL. Racial residential segregation and geographic heterogeneity in black/white disparity in poor self-rated health in the US: a multilevel statistical analysis. Soc Sci Med. 2005; 60:1667-1679. [PubMed: 15686800]

US Census Bureau. [Accessed 9/20/2010] Summary File 4: Technical Documentation; 2000. p. 1http:// www.census.gov/prod/cen2000/doc/sf4.pdfchapter 5

Wadhwa PD, Culhane JF, Rauh V, Barve SS. Stress and preterm birth: neuroendocrine, immune/ inflammatory, and vascular mechanisms. Matern Child Health J. 2001a; 5:119-125. [PubMed: 11573837]

Wadhwa PD, Culhane JF, Rauh V, Barve SS, Hogan V, Sandman CA, Hobel CJ, Chicz-Demet A, Dunkel-Schetter C, Garite TJ, Glynn L. Stress, infection and preterm birth: a biobehavioural perspective. Paediatr Perinat Epidemiol. 2001b; 15(Suppl 2):17-29. [PubMed: 11520397]

Walton E. Residential Segregation and Birth Weight among Racial and Ethnic Minorities in the United States. J Health Soc Behav. 2009; 50:427-442. [PubMed: 20099449] 
White K, Borrell LN. Racial/ethnic neighborhood concentration and self-reported health in New York City. Ethn Dis. 2006; 16:900-908. [PubMed: 17061744]

Williams RL. A note on robust variance estimation for cluster-correlated data. Biometrics. 2000; 56:645-646. [PubMed: 10877330] 


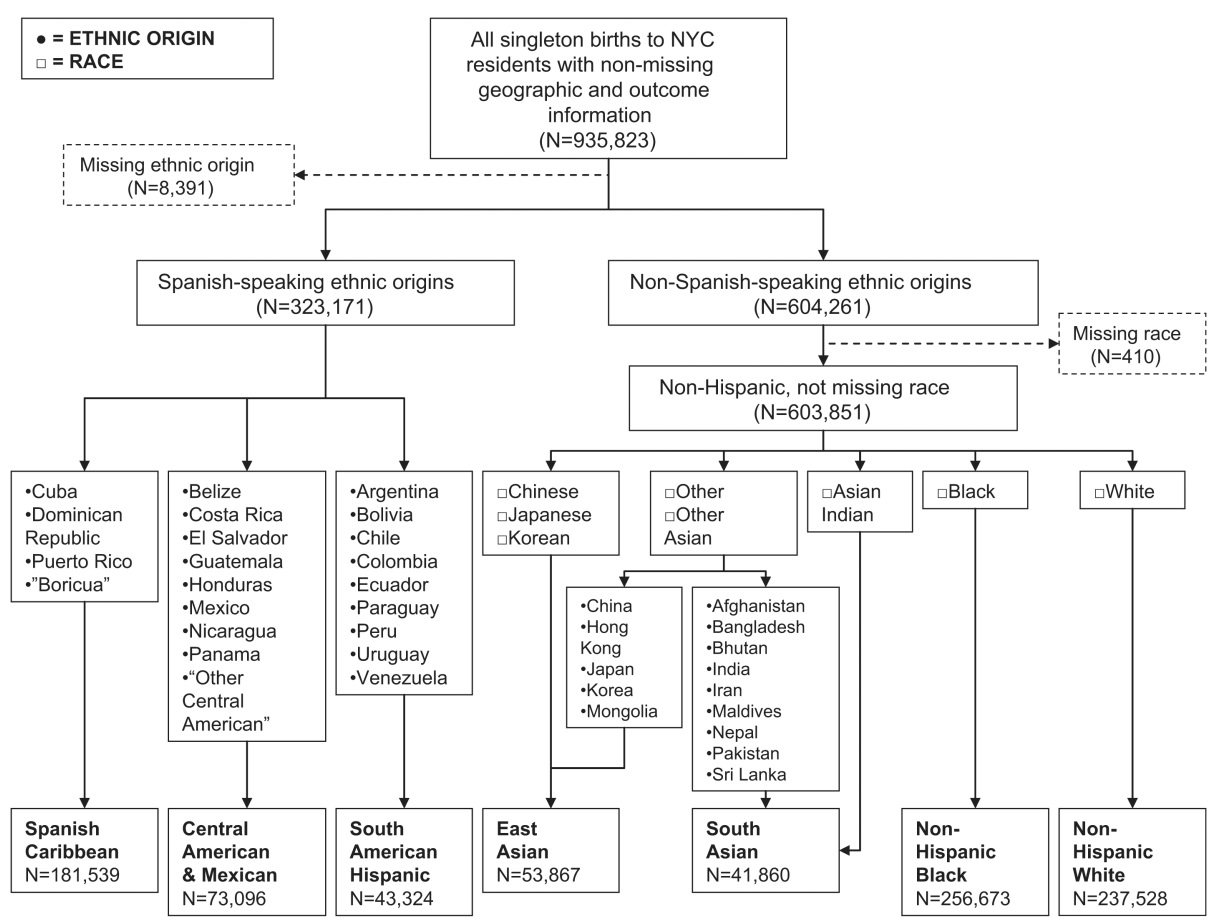

Fig. 1.

Identification of seven maternal ethnic groups from the New York City birth records for 1995 through 2003. Dashed lines indicate births that could not be included due to missing race or ethnicity information. 


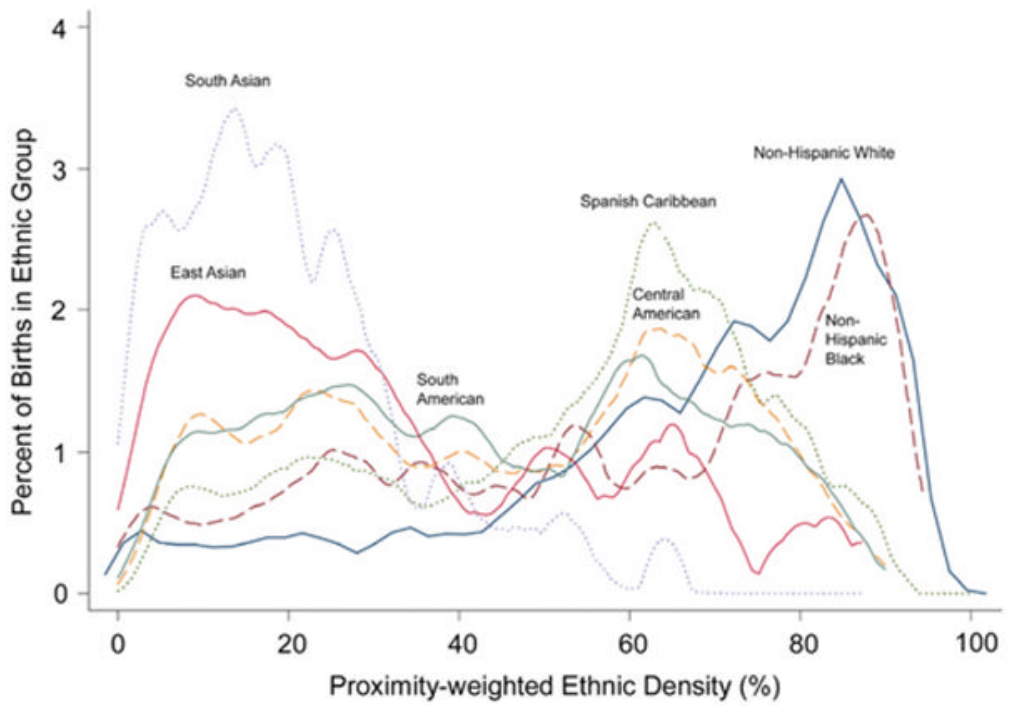

Fig. 2.

Distribution of births in seven ethnic groups across the range of ethnic density in the maternal neighborhood: New York City, 1995-2003. (Kernel smoothed; kernel=Epanechnikov, bandwidth=0.02). 


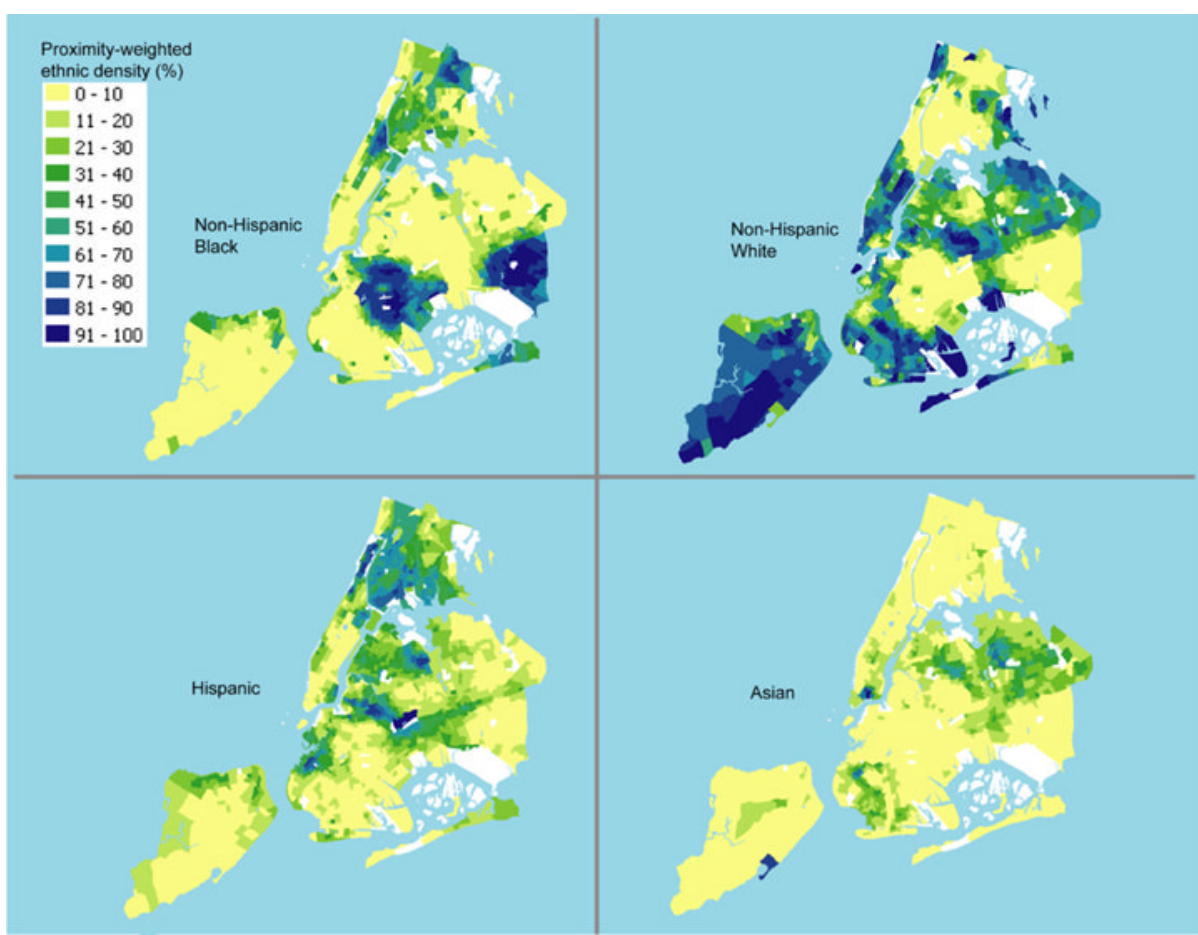

Fig. 3.

Geographic distribution, by census tract, of four ethnic densities measured with a 500-meter radius: New York City, 2000 US Census. 


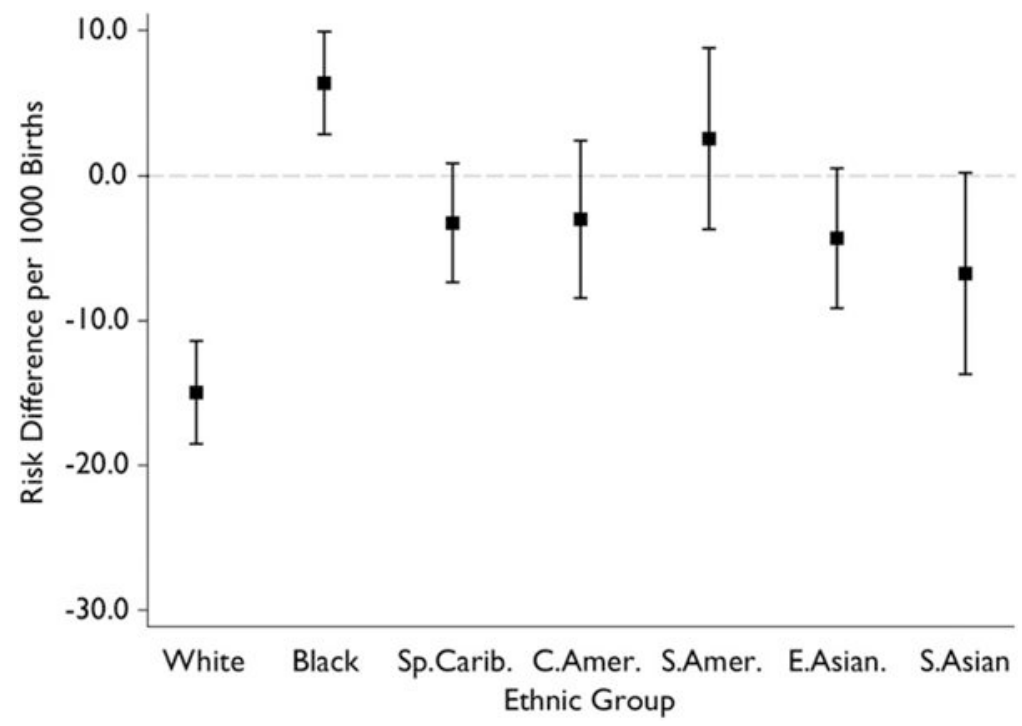

Fig. 4.

Adjusted risk differences with $95 \%$ confidence intervals for preterm birth among seven ethnic groups associated with residence in an ethnic enclave ( $>25 \%$ ethnic density): New York City 1995-2003. Adjusted risk differences were calculated for US-born women aged 20-34 who were high-school educated, had 2-5 previous live births, were nonsmokers, received Medicaid, and resided in a more stable and poorer neighborhood. White=nonHispanic white; Black=non-Hispanic black; Sp.Carib=Spanish Caribbean; C.Amer=Central American; S.Amer=South American; E.Asian=East Asian; S.Asian=South Asian. 


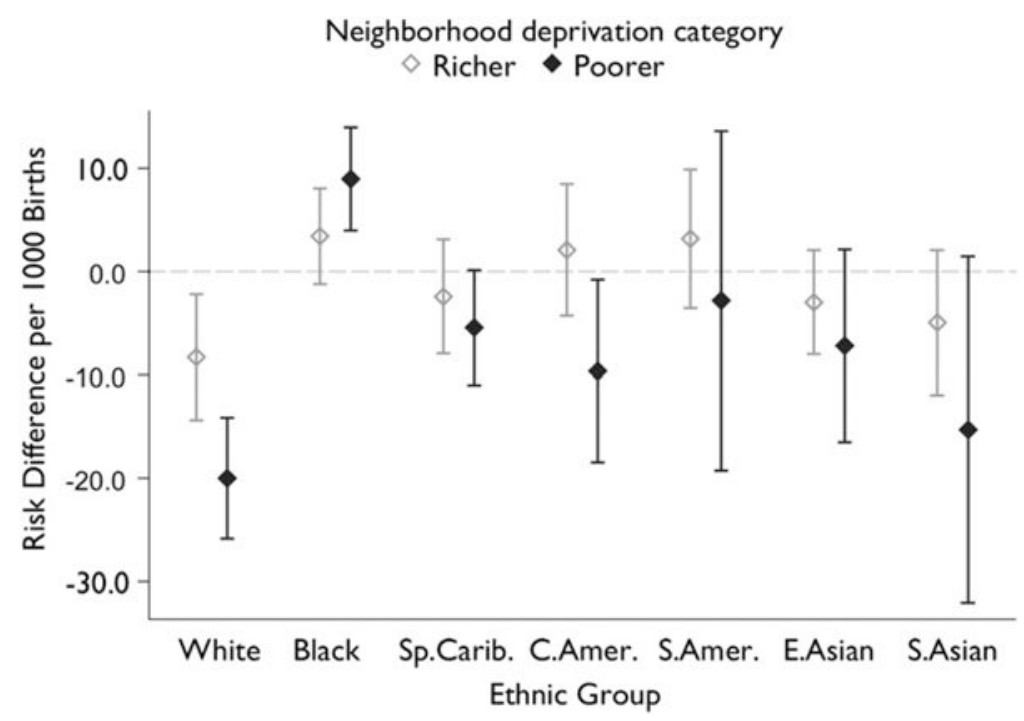

Fig. 5.

Neighborhood deprivation-stratified risk differences with $95 \%$ confidence intervals for preterm birth among seven ethnic groups associated with residence in an ethnic enclave (> 25\% ethnic density): New York City 1995-2003. Risk differences were calculated for USborn women aged 20-34 who were high-school educated, had 2-5 previous live births, were nonsmokers, received Medicaid, and resided in a more stable neighborhood. White=nonHispanic white; Black=non-Hispanic black; Sp.Carib=Spanish Caribbean; C.Amer=Central American; S.Amer=South American; E.Asian=East Asian; S.Asian=South Asian. 


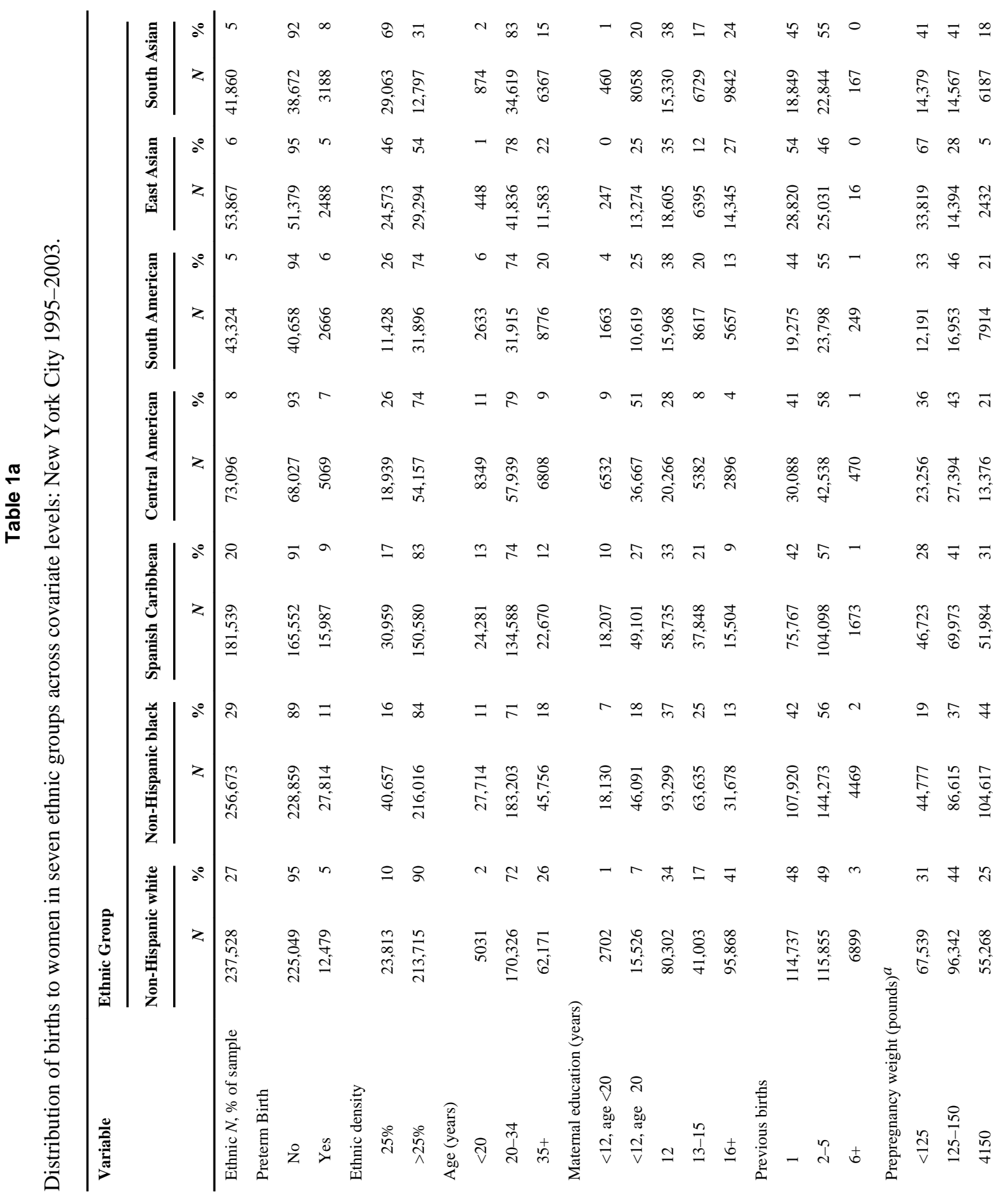




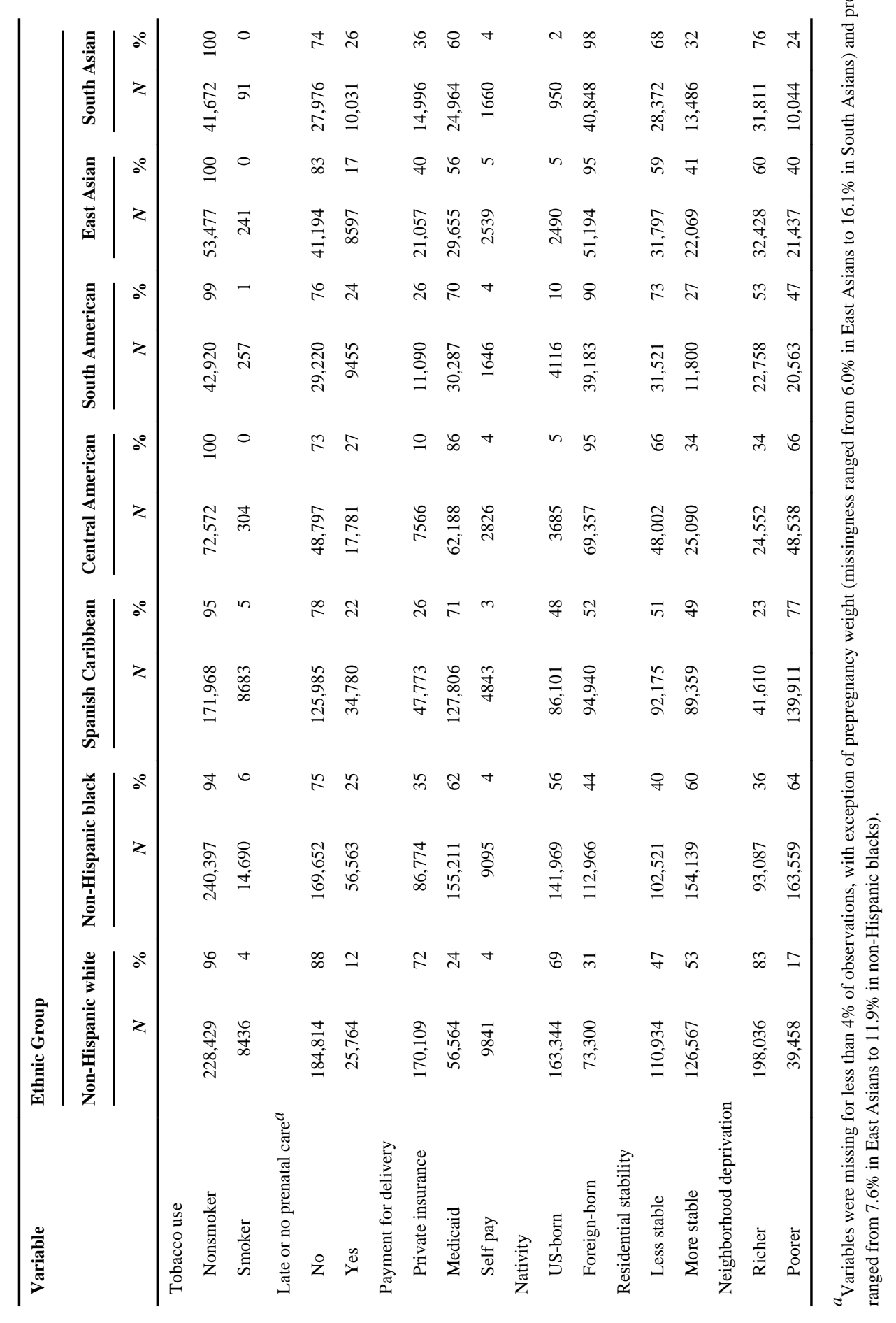


Table 1b

Distribution of census tracts across neighborhood-level covariates: New York City 1995-2003.

\begin{tabular}{|c|c|c|}
\hline Neighborhood-level covariate & $N$ & $\%$ \\
\hline \multicolumn{3}{|l|}{ Non-Hispanic white ethnic density } \\
\hline$\preceq 25 \%$ & 1084 & 50 \\
\hline$>25 \%$ & 1072 & 50 \\
\hline \multicolumn{3}{|l|}{ Non-Hispanic black ethnic density } \\
\hline 노\% & 1359 & 63 \\
\hline$>25 \%$ & 797 & 37 \\
\hline \multicolumn{3}{|l|}{ Hispanic ethnic density } \\
\hline s25\% & 1341 & 62 \\
\hline$>25 \%$ & 815 & 38 \\
\hline \multicolumn{3}{|l|}{ Asian ethnic density } \\
\hline 누\% & 1942 & 90 \\
\hline$>25 \%$ & 214 & 10 \\
\hline \multicolumn{3}{|l|}{ Residential stability } \\
\hline Less stable & 1015 & 47 \\
\hline More stable & 1134 & 53 \\
\hline \multicolumn{3}{|l|}{ Neighborhood deprivation } \\
\hline Richer & 1394 & 65 \\
\hline Poorer & 750 & 35 \\
\hline
\end{tabular}


Table 2

Difference in preterm birth risk (per 1000 births) associated with maternal residence in an ethnic enclave (> 25\% ethnic group) for seven ethnic groups: New York City, 1995-2003.

\begin{tabular}{lllll}
\hline Ethnic Group & Model & & \\
\cline { 2 - 5 } & Crude & Adjusted & Stratified: Richer Neighborhoods & Stratified: Poorer Neighborhoods \\
\cline { 2 - 5 } & $\mathbf{R D}^{\boldsymbol{a}(\mathbf{9 5} \% \mathbf{C I})}$ & $\mathbf{R D}^{\boldsymbol{a}} \mathbf{( 9 5 \% \mathbf { C I } )}$ & $\mathbf{R D}^{\boldsymbol{a}}(\mathbf{9 5} \% \mathbf{C I})$ & $\mathbf{R D}^{\boldsymbol{a}}\left(\mathbf{9 5 \%} \mathbf{C I}^{\mathbf{9}}\right)$ \\
\hline Non-Hispanic white & $-17.0(-20.9,-13.1)$ & $-15.0(-18.5,-11.4)$ & $-8.3(-14.4,-2.2)$ & $-20.0(-25.9,-14.1)$ \\
Non-Hispanic black & $9.5(6.0,13.1)$ & $6.4(2.8,9.9)$ & $3.4(-1.2,8.1)$ & $9.0(4.0,14.0)$ \\
Spanish Caribbean & $-3.6(-7.4,0.2)$ & $-3.3(-7.4,0.8)$ & $-2.4(-7.9,3.1)$ & $-5.4(-10.9,0.1)$ \\
Central American & $-3.2(-7.9,1.5)$ & $-3.0(-8.5,2.4)$ & $2.1(-4.2,8.5)$ & $-9.6(-18.5,-0.8)$ \\
South American & $1.0(-4.1,6.1)$ & $2.5(-3.7,8.8)$ & $3.2(-3.5,9.9)$ & $-2.8(-19.3,13.6)$ \\
East Asian & $-3.7(-7.4,-0.1)$ & $-4.3(-9.1,0.5)$ & $-3.0(-8.0,2.1)$ & $-7.2(-16.5,2.1)$ \\
South Asian & $-9.3(-16.0,-2.6)$ & $-6.7(-13.7,0.2)$ & $-4.9(-11.9,2.1)$ & $-15.3(-32.0,1.4)$ \\
\hline
\end{tabular}

${ }^{a} \mathrm{RD}=$ risk difference; adjusted and stratified RDs were calculated for US-born women aged 20-34 who were high-school educated, had 2-5 previous live births, were nonsmokers, received Medicaid, and resided in a more stable and (for adjusted estimates) poorer neighborhood. 